
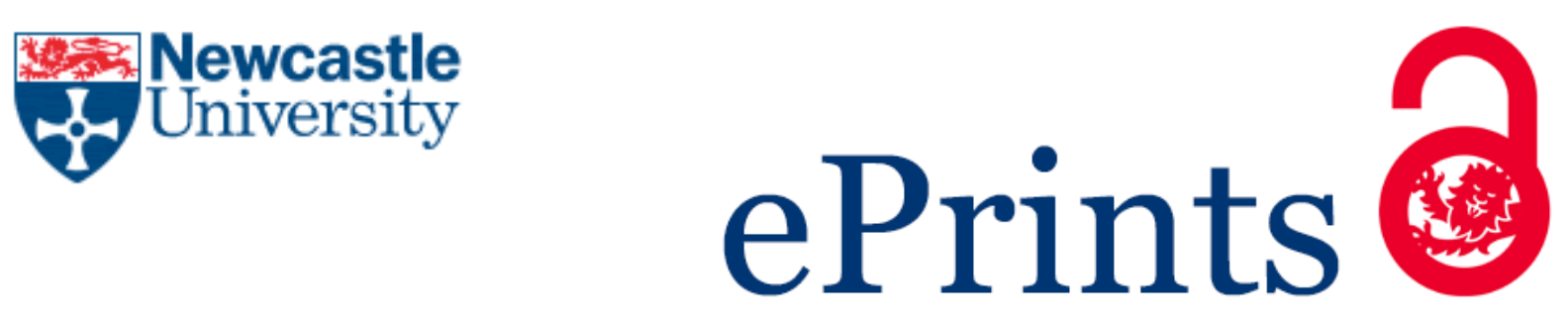

Kulan M, Baker NJ, Widmer J.

Design and Analysis of Compressed Windings for a Permanent Magnet

Integrated Starter Generator.

IEEE Transactions on Industry Applications 2017, https://doi.org/10.1109/TIA.2017.2681976

\title{
Copyright:
}

(C) 2017 IEEE. Personal use of this material is permitted. Permission from IEEE must be obtained for all other uses, in any current or future media, including reprinting/republishing this material for advertising or promotional purposes, creating new collective works, for resale or redistribution to servers or lists, or reuse of any copyrighted component of this work in other works.

DOI link to article:

https://doi.org/10.1109/TIA.2017.2681976

Date deposited:

$04 / 04 / 2017$ 


\section{Design and Analysis of Compressed Windings for a Permanent Magnet Integrated Starter Generator}

\author{
Mehmet C. Kulan \\ Newcastle University \\ Newcastle Upon Tyne, NE1 4NF, UK \\ m.c.kulan@newcastle.ac.uk
}

\author{
Nick J. Baker \\ Newcastle University \\ Newcastle Upon Tyne, NE1 4NF, UK \\ Nick.baker@newcastle.ac.uk
}

\begin{abstract}
This paper focuses on the improved thermal performance of electrical machines by increasing the conductor fill factor. A comparative design study of integrated starter generator (ISG) is used as a case study to investigate the mechanical, electrical and thermal aspects of pressing coils. By performing quasi-static explicit dynamic simulations, deformation of insulation has been investigated. $1.25 \mathrm{~mm}$ diameter magnet wires are simulated and demonstrated to be compressible up to a 0.73 fill factor without observing insulation failure. Thermal conductivity enhancement of the stator windings at improved slot fill factor is investigated by performing steady state FEA thermal simulations and short time thermal transient tests.
\end{abstract}

Index Terms-- Integrated starter generator, permanent magnet machines, quasi-static explicit dynamics modelling, slot fill factor, thermal conductivity of windings, compressed stator windings

\section{INTRODUCTION}

$\mathrm{E}$ lectrification of the automotive sector has received great interest recently as it may represent a way of reducing road traffic emissions and improving fuel usage. The Integrated Starter Generator (ISG) is one such enabling technology. Induction, transverse flux, switched reluctance, doubly salient, wound field brushless and brushless permanent magnet machines have all been proposed for ISGs [1-5].

In other applications, various methods have been investigated to obtain higher fill factors and improve performance, such as segmented stators coupled with prepressed windings [7-9]. This paper uses the design of a crankshaft mounted ISG to investigate the limits of machine performance improvement achieved by pressing the coils as previously discussed in [6]. In addition to reducing DC winding loss and improving heat transfer, compression of stator windings by applying 200-800 MPa of pressure can potentially deform and deteriorate wire insulation. To investigate whether insulation failure occurs, the dynamic behavior of coil pressing requires the use of quasi-static explicit dynamics modelling to get accurate stress and strain calculations due to the highly non-linear and deformed geometries [10]. Performing this type of finite element analysis (FEA) modelling produces results for detecting deformation of wire enamels by analyzing equivalent Von Mises stress and plastic strain results.
This paper uses an ISG as a case study for copper loss reduction via compressing the windings. Quasi-static explicit dynamic modeling, validated by experimental results, is used to demonstrate a suitable method of coil compression without losing insulation integrity.

Finally, thermal improvements due to high fill factor windings have been investigated by performing thermal FEA simulations and short time thermal transient tests of a motorette in the laboratory.

\section{ISG MACHINE DESIGN}

\section{A. Proposed ISG Structures and Optimization}

Typical ISGs have maximum low speed instantaneous torques of greater than $170 \mathrm{Nm}$, for a cold start, whilst being capable of delivering over $90 \%$ efficiency at high speed when operating as a generator. Size constraints imposed by the existing drive train require the use of high torque density machines. Key machine parameters are shown in Table I for a typical specification [5]. Note the large shaft diameter to accommodate existing shape of the vehicle clutch.

TABLE I. Key Machine PARAMETERS

\begin{tabular}{cc}
\hline Stator outer diameter & $290 \mathrm{~mm}$ \\
Shaft diameter & $150 \mathrm{~mm}$ \\
Axial length & $40 \mathrm{~mm}$ \\
Efficiency, $50 \mathrm{Nm}$ torque at $1500 \mathrm{rpm}$ & $93 \%$ \\
Motor mode shaft torque at $200 \mathrm{rpm}$ & $180 \mathrm{Nm}$ \\
Maximum DC bus voltage & $350 \mathrm{~V}$ \\
Generator mode power at 2000-5000 rpm & $22 \mathrm{~kW}$ \\
Surrounding temperature at generator mode & $95^{\circ} \mathrm{C}$ \\
Surrounding temperature at motor mode & $-30^{\circ} \mathrm{C}$ \\
Liquid Cooling system & 6 litre $/ \mathrm{min}$ \\
\hline
\end{tabular}

From the efficiency point of view, PM machines with 8 to 12 poles are preferable for ISGs. Peculiarities of this ISG drive are its relatively large shaft and external diameters compared to traditional ISG systems as discussed in [11][12]. For this reason, 18 slot/10 pole and 21 slot/16 pole ISG configurations were investigated. The ISG should provide continuous power over a wide speed range in generator mode, 
implying surface mounted PM machines are not appropriate as there is no significant salient effect due to negligible difference between d- and q- axis reluctance. V-shape interior PM machine for ISG systems were discussed in [13]. It was shown that $\mathrm{V}$-shape PM machines have many advantages for traction motor applications such as reduced magnet mass and loss, greater saliency ratio. This has been verified for an external rotor machine in [14].

Detailed selection of ISG configurations was given in [6] involving the use of an optimization routine who's weighted objective function is targeted at reducing magnet mass (0.3), torque ripple (0.3) and machine losses at $1500 \mathrm{rpm}(0.4)$.

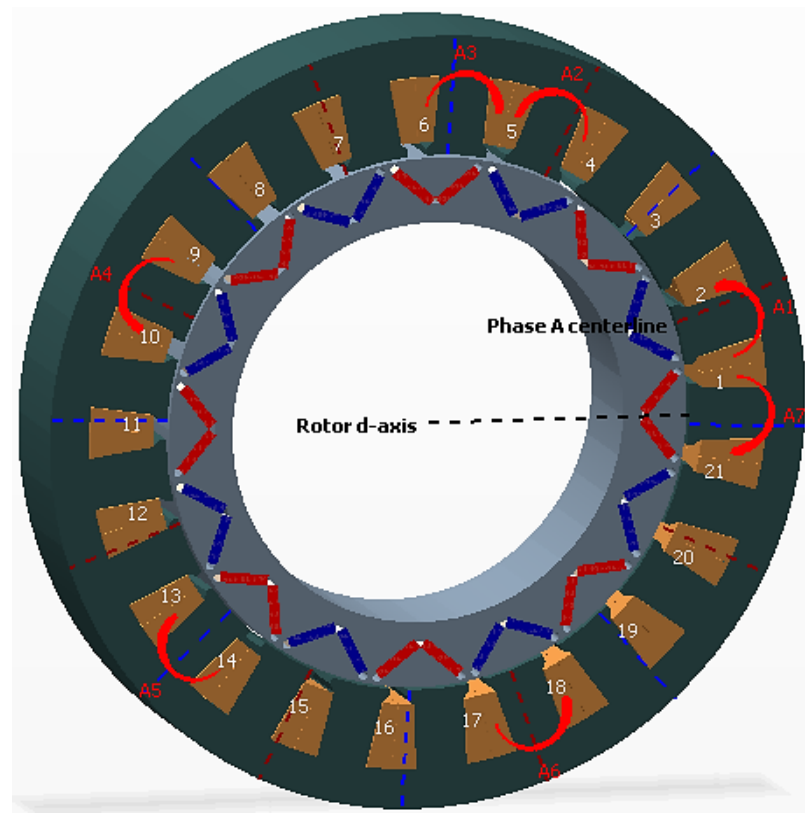

Fig. 1. Proposed 21 slot /16 pole PM ISG configuration depicting winding configuration for a single phase - MotorSolve by Infolytica prototype geometry

The proposed design is shown in Fig. 1, as a 21 slot/16 pole interior V-shape PM ISG. This machine will be used as a case study for the investigation of electrical and thermal advantages of compressed stator windings over random wound conventional windings. Physical performance parameters are given in Table II.

TABLE II. PERFORMANCE PARAMETERS OF THE V-SHAPE ISG

\begin{tabular}{cc}
\hline Parameter & Values \\
\hline Rotor inner diameter & $150 \mathrm{~mm}$ \\
Rotor outer diameter & $198.7 \mathrm{~mm}$ \\
Air gap length & $1 \mathrm{~mm}$ \\
Stator outer diameter & $290 \mathrm{~mm}$ \\
Magnet mass & $0.71 \mathrm{~kg}$ \\
Slot area & $388 \mathrm{~mm}^{2}$ \\
Number of turns & 13 \\
Slot fill factor & 0.45 \\
\hline
\end{tabular}

Current density at motor mode $-200 \mathrm{rpm}, 180$ $\mathrm{Nm}$ for $10 \mathrm{~s}$

Current density at generator mode $-1500 \mathrm{rpm}$, $50 \mathrm{Nm}$

$20 A_{r m s} / \mathrm{mm}^{2}$

Current density at generator mode $-2000 \mathrm{rpm}$, $105.5 \mathrm{Nm}$

$5 A_{r m s} / \mathrm{mm}^{2}$ Efficiency at $1500 \mathrm{rpm}$

$10.5 A_{r m s} / \mathrm{mm}^{2}$ $96.7 \%$

\section{Performance Improvement With InCREASEd FiLL FACTOR}

The machine performance has been studied in continuous generating mode at $1500 \mathrm{rpm}$, where minimum efficiency must be $93 \%$. The slot fill factor was assumed to be 0.45 in Table II as number of turns is low and conductor crosssectional area is relatively large $(2.9 \mathrm{~mm})$ resulting in gaps between the round copper wires. The winding configuration was altered from a series to parallel connection, and the wire diameter reduced to increase the number of turns from 13 to 91 for each stator tooth. If the stator is segmented, a higher fill factor could be achieved due to modularity making it easier to wind. The modular stator segments are shown in Fig. 2.

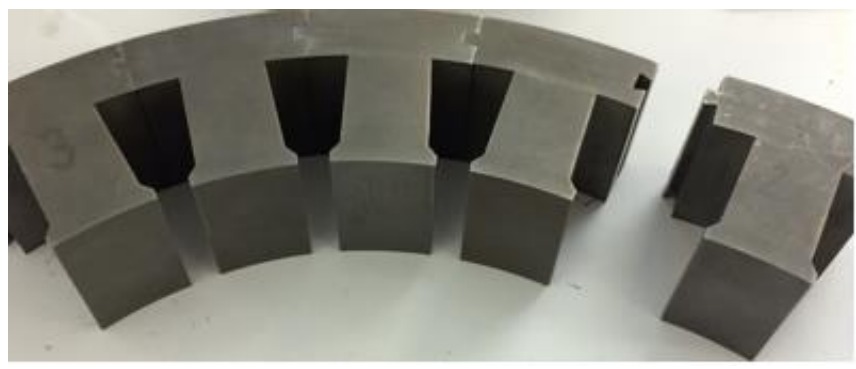

Fig. 2. Modular stator teeth for the proposed ISG

Table III shows estimated variation of achievable fill factor considering traditional stator manufacturing, modular stator manufacturing and also modular stator manufacturing with on-tooth compressed coils. A fill factor of 0.73 is later shown to be achievable using on tooth pressing in Section IV.

TABLE III. IMPROVEMENT OF FILL FACTOR

\begin{tabular}{c|c|c|c}
\hline & $\begin{array}{c}\text { Traditional } \\
\text { stator }\end{array}$ & $\begin{array}{c}\text { Segmented } \\
\text { stator }\end{array}$ & $\begin{array}{c}\text { On-tooth } \\
\text { pressed coil }\end{array}$ \\
\hline Fill Factor & 0.45 & 0.65 & 0.73 \\
\hline $\begin{array}{c}\text { Number of turns } \\
\text { (series vs parallel) }\end{array}$ & 13 & 91 & 91 \\
\hline $\begin{array}{c}\text { Copper area }\left(\mathrm{mm}^{2}\right) \\
\begin{array}{c}\text { Copper loss at 1500 rpm - generator } \\
\text { mode }(\text { Watt })\end{array}\end{array}$ & 140.4 & 97.2 & 86.58 \\
\hline $\begin{array}{c}\text { Drive current when copper loss is } \\
\text { kept at 140.4 watts maximum } \\
\left(\mathrm{A}_{\text {rms })}\right.\end{array}$ & 34 & 57.7 & 61.1 \\
\hline
\end{tabular}

The reduction of copper losses in the segmented stator in 
Table III is due to parallel connection of the ISG teeth with an estimated fill factor of 0.65 . The further reduction of copper losses could be achieved by on-tooth pressing since relatively thicker conductors are densely packed in the slot area. In Table III, increasing slot fill factor from 0.45 to 0.73 results in copper losses being reduced by almost $38 \%$. This prediction is based on only fill factor and bulk copper area inside the slot. In the real prototype, copper loss reduction is also dependent on commercially available conductor sizes. Alternatively as given in Table III, the ISG can be loaded with more current for the same copper losses, increasing machine torque density. In addition, as pressing the coil enhances thermal contact conductance between the conductors, the effective thermal conductivity of the slot would be improved in this case.

\section{Structural ANALYSIS OF COIL PRESSING}

$1.25 \mathrm{~mm}$ and $1.4 \mathrm{~mm}$ conductor diameters have been identified as facilitating high fill factors. $1.25 \mathrm{~mm}$ Grade- 2 copper magnet wire was chosen for the ISG as compressibility of a greater number of turns and thinner conductor is much better than thicker conductors.

Quasi-static explicit dynamics simulations have been conducted to investigate the maximum improvement in fill factor without damaging magnet wire insulation.

\section{A. Quasi-static Explicit Dynamics Simulations}

Transient dynamic simulations usually require extremely small time steps to converge an accurate solution. There are two types of time integration methods: implicit and explicit methods. Since explicit methods are very efficient for each time step, it will allow calculation of a very large number of time steps within the duration of simulation time. If the dynamic response of a system takes a few seconds rather than a few milliseconds, then many millions of time steps will be required to observe the complete dynamic behavior of the system. This type of FEA analysis is required for certain physical problems.

In order to solve highly non-linear problems, special types of FEA packages could be utilized. Explicit Dynamics analysis system which is available in Ansys CAE package is the most appropriate choice for coil pressing simulations in comparison to transient structural simulation tools.

Dynamic modelling of a coil pressing requires accurate nodal stress-strain calculations. This is only possible by conducting quasi-static dynamic modelling of the coil pressing. This type of simulation is challenging as time integration is dependent on minimum element size in the meshed model. This is given in (1).

$$
\Delta t \leq \frac{h}{c}
$$

In (1), $\Delta t$ is integration time step, $h$ is the smallest element size and $c$ is the wave speed of the material. It is clear that $\Delta t$ is a function of the minimum element size. Since film insulation thickness usually varies between 0.05 to about $0.1 \mathrm{~mm}$ in magnet wires, time step of the coil pressing simulations will be controlled by the element size in the magnet wire enamel. Therefore, these simulations with refined mesh will be too costly computationally.

As quasi-static coil pressing simulations take too much time to converge a solution, several methods have been implemented to simulate the dynamic behavior of the coil pressing model in a reasonable time, discussed in [15] in detail. Increasing the loading rates exerted on a punch can be implemented to press the coil in relatively smaller time amount. The pros and cons of this approach are as follows [15]:

1) Artificially increasing the speed of the process in the simulation is often required to obtain an economical solution.

2) Material strain rates calculated in the simulation are artificially high by the same factor applied to increase the loading rate.

Although increasing the loading rates artificially increases the calculated nodal strain rates, these results can be downscaled by the same factor used to increase the speed of the compression. Thus, the material fracture can be predicted by inspecting equivalent von-Mises stress and plastic strain results, scaling accordingly.

\section{B. FEA of Coil Pressing}

The process of coil pressing is investigated by modelling a 5 layer, 15 turn polyimide enameled magnet wire with conductor diameter $1.25 \mathrm{~mm}$ and $0.05 \mathrm{~mm}$ insulation thickness. Quasi-static explicit dynamic simulations have been performed with the mechanical properties of polyimide insulation given in Table IV.

TABLE IV. MATERIAL PROPERTIES OF POLYIMIDE

\begin{tabular}{ccc}
\hline Density & $1.3 \times 10^{3}-1.8 \times 10^{3}$ & $\mathrm{~kg} / \mathrm{m}^{3}$ \\
Young's Modulus & $2.44-4$ & $\mathrm{GPa}$ \\
Shear Modulus & $0.91-0.955$ & $\mathrm{GPa}$ \\
Yield Strength & $72-158$ & $\mathrm{MPa}$ \\
Compressive Strength & $133-227$ & $\mathrm{MPa}$ \\
Fracture Strength & 345 & $\mathrm{MPa}$ \\
Elongation & $2-3$ & $\mathrm{~mm} / \mathrm{mm}$ \\
\hline
\end{tabular}

Young's modulus of copper is around $120 \mathrm{GPa}$, yet Young's modulus of thermoset polymers is less than $4 G P a$, confirming the mechanical weakness in the winding is the coating. When coil pressing simulations are monitored to detect insulation failure, elongation and fracture strength of the insulation should be compared to simulation results as they imply material fracture at certain stress and strain values. 
Compression of the coil is achieved by applying a velocity load onto the Steel punch to control the total displacement. As complex body-contact conditions, large deformations and material non-linearity are present, a mesh dominated by tetrahedron elements will not generate accurate deformation results, as clearly illustrated in the unrealistic predicted deformation in Fig. 3. Tetrahedrons cannot fill the given volume efficiently and so a hexahedron dominant mesh is used as recommended in [16].

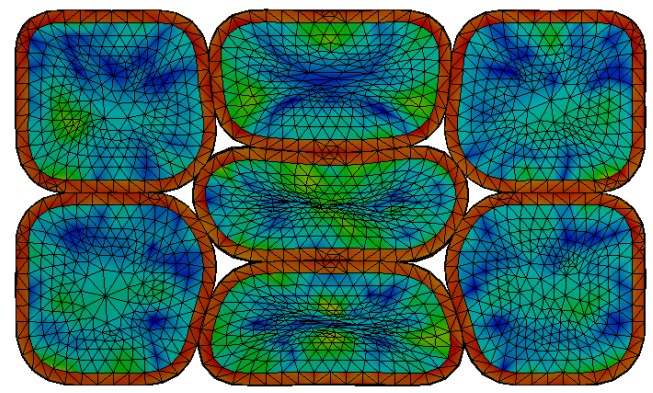

Fig. 3. Unrealistic deformation of a coil with tetrahedron dominant mesh

Unbreakable bonded contact was provided between the copper wire and its enamel. Also, frictional turn to turn body interaction with a coefficient 0.2 was applied to the model. Since increasing loading rates might increase contact interpenetration, velocity of the punch was optimized by performing several simulations. The software uses default pure-penalty method to solve body interactions. The simulation setup is shown in Fig. 4.

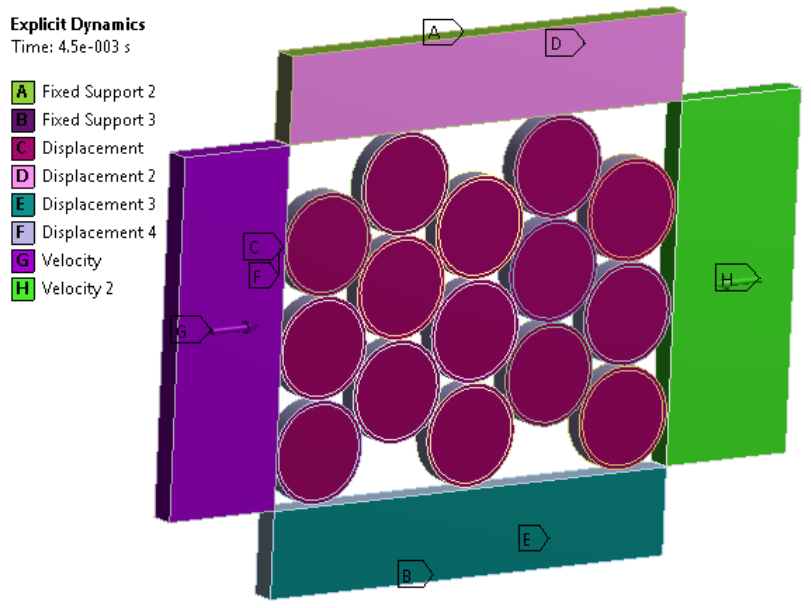

Fig. 4. FEA boundary conditions for quasi-static pressing

The simulation is artificially accelerated to press the coil over a very small amount of time due to computational cost of the explicit dynamic systems. This model has been solved in about 40 hours with 4- core, 24 GB memory PC to see the total dynamic response of the system. Note that if natural time of the coil pressing event was used for the models to obtain the original plastic strain results, converging to a B: $1.25 \mathrm{~mm}$ Grade-2 Equivalent Stress

Type: Equivalent (von-Mises) Stress Unit: $\mathrm{MPa}$

Time: $3.6 \mathrm{e}-003$

$449.92 \mathrm{Max}$

343.06

300.18

257.3

214.41 solution would take about 4000 hours. The applied velocity functions with respect to time are shown in Fig. 5.

Time integration of the velocity profile gives the total displacement of the punch as $0.479 \mathrm{~mm}$ and the maximum speed of the punch is $300 \mathrm{~mm} / \mathrm{s}$, corresponding to a $30 \mathrm{~cm}$ displacement in one second. Clearly, the speed of punch does not reflect natural time of the event as coil pressing cannot be achieved in a few milliseconds in reality. The actual speed of the press is assumed to be at least 100 times slower than this. Therefore, simulated results of the compression process need to be scaled down a hundred times.

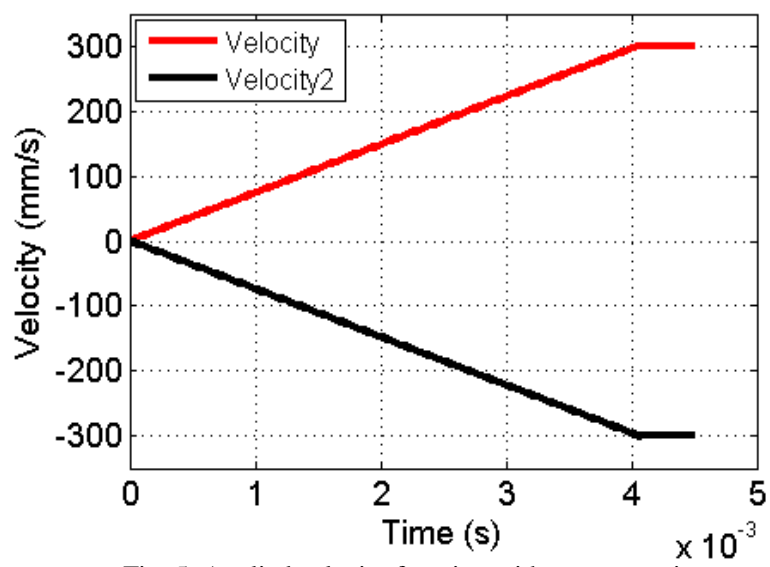

Fig. 5. Applied velocity function with respect to time

\section{Quasi-Static FEA Results}

Fig. 6 shows the FEA results of a 15-turn coil pressed by applying horizontal load to permanently deform the coil. Results shown are for the final time instant before material fracture occurs on wire enamels.

Equivalent von-Mises stress and plastic strain results are monitored during the dynamic response of the compression to investigate insulation failure. In Fig. 6a, maximum equivalent von-Mises stress is $449.9 \mathrm{MPa}$. All magnet wires experience significant plastic deformation. Equivalent plastic strain rate on the magnet wire enamels is the most important indicator to detect material fracture. Since simulated material strain rates are increased by the same factor as the loading rate, plastic predicted strain rates are more than 100 times greater than reality. Corrected strain rates are $0.013 \mathrm{~mm} / \mathrm{mm}$ on the magnet wire enamel and elongation of polyimide thermosets is $0.03 \mathrm{~mm} / \mathrm{mm}$. The insulation is still safe as the wire has not elongated more than the insulation. Moreover, equivalent von-Mises stress on the insulation is shown in Fig. $6 \mathrm{~b}$ to peak at $230.4 \mathrm{MPa}$, less than the fracture strength of polyimide of $345 \mathrm{MPa}$. Thus, magnet wires with $1.25 \mathrm{~mm}$ conductor diameter are predicted to be safely compressed to a 0.73 fill factor. 
a)

b)

c)

Fig. 6. (a) Equivalent von-Mises stress on magnet wires, (b) Equivalent von-Mises stress on wire insulations, (c) Plastic strain on wire insulation

\section{Experimental pressing results}

Fig. 7 shows that predicted deformation is mostly seen for the regions between steel cavity and magnet wire enamel since friction coefficient between steel and wire enamel is greater than that of inter-turn contact regions. This condition is sometimes encountered in experimental coil pressing (Fig. 7). In order to prevent this, cavities of a die built for coil pressing must consider the bend radius of the end windings, as it expands while pressing the bobbin. End winding deformation can be mitigated by proper design of die cavity used for compression of bobbins, it is not necessary to compress end windings to obtain higher slot fill factors.

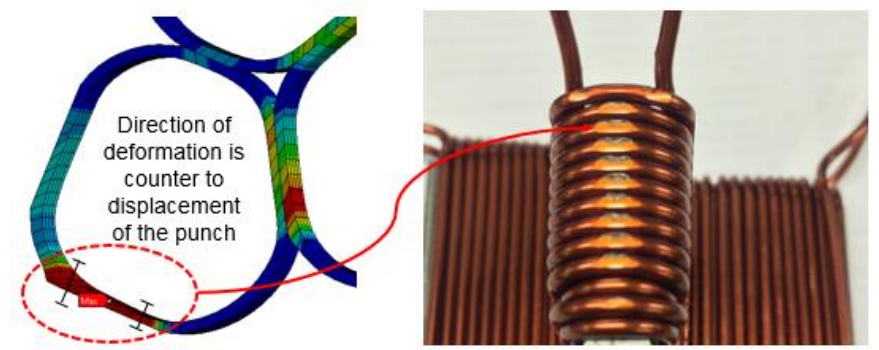

Fig. 7. Deformation of end windings insulation during compression

Therefore, a method of on-tooth pressing has been applied to compress only lateral surfaces of a single tooth winding. In Fig. 8, the structure of pressing tools is given. As a result of quasi static FEA simulations, it was shown that around 0.73 fill factor is achievable for Grade-2, $1.25 \mathrm{~mm}$ round copper wires. Further compression in this case results in material failure on wire enamels.

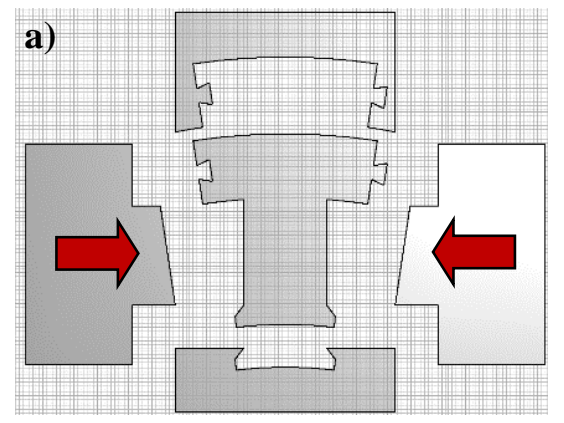

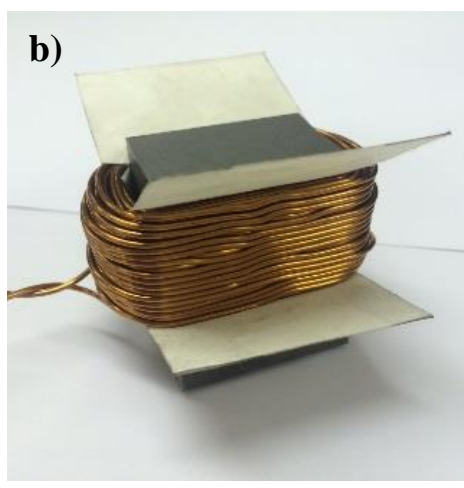

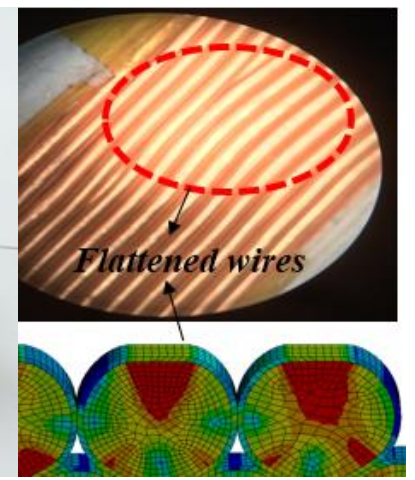

Fig. 8. (a) Structure of coil pressing, (b) a compressed ISG single tooth winding with deformed magnet wires

For electrical insulation, Nomex sheets with $0.25 \mathrm{~mm}$ thickness were used. A 0.72 slot fill factor has been achieved experimentally by compression of the windings. From a macroscopic point of view, there was not any insulation damage on the compressed windings. The lateral surfaces of the winding, however, flatten when a high pressure is applied onto the punches (10 to 14 tonnes). The flattened surfaces on the round wires were also observed in the deformed FEA results (Fig. 6b).

IEEE 43 standard [17] states that random wound stator coils rated below $1 \mathrm{kV}$ must have minimum $5 \mathrm{M} \Omega$ insulation resistance. Turn to ground high voltage tests were carried out on the pressed coils and no insulation failure has been observed as this standard was satisfied with measured insulation resistances varying around $2700 \mathrm{M} \Omega$ during electrical tests. Coil deformation and preservation of the insulation are therefore both in line with simulated results.

\section{THERMAL ANALYSIS OF COIL PRESSING}

Important thermal parameters of an electrical machine are dependent on manufacturing methods and on-tooth coil pressing will change the thermal parameters of the winding samples. It is known that thermal parameters are strongly influenced by critical thermal parameters [18] such as equivalent slot thermal conductivity, heat transfer coefficients for external surfaces and interface gaps between the machine parts. Thermal resistivity of the random wound coil is one of 
those parameters and it should be estimated accurately to model the machine thermally.

\section{A. Slot Thermal Conductivity Prediction}

In the literature, a number of models have been proposed to obtain equivalent thermal model of round copper stator windings [19-20]. One approach is based on extensive experimental tests to predict equivalent thermal conductivity [20]. For this reason, a thermal FEA simulations based approach has been developed to estimate equivalent slot thermal conductivity of the compressed ISG stator segments. The calculation method is based on the one-dimensional Fourier law of heat as given in (2).

$$
Q=-k \frac{\partial T}{\partial X}=-k\left[\frac{T_{x=l}-T_{x=0}}{l}\right]=>k=\frac{Q \times l}{\Delta T}
$$

Where $\partial T / \partial x$ is temperature gradient for a distance $l(m)$ and $k(W / m K)$ stands for thermal conductivity. $Q(W /$ $\mathrm{m}^{2}$ ) is heat flux density in one dimension. Whilst heat flows in a winding segment, heat flux passes through copper, wire insulation and air pockets inside the windings. Table $\mathrm{V}$ shows the isotropic thermal conductivity of the stator winding materials including slot liner at room temperature.

TABLE V. THERMAL CONDUCTIVITIES FOR THE MATERIALS

\begin{tabular}{l|l|l|}
\hline Material & Thermal Conductivity & Unit \\
\hline Air & 0.026 & $W m^{-1} K^{-1}$ \\
Polyimide & 0.25 & $W m^{-1} K^{-1}$ \\
Copper & 400 & $W m^{-1} K^{-1}$ \\
\hline Nomex & 0.14 & First \\
\hline
\end{tabular}

a)

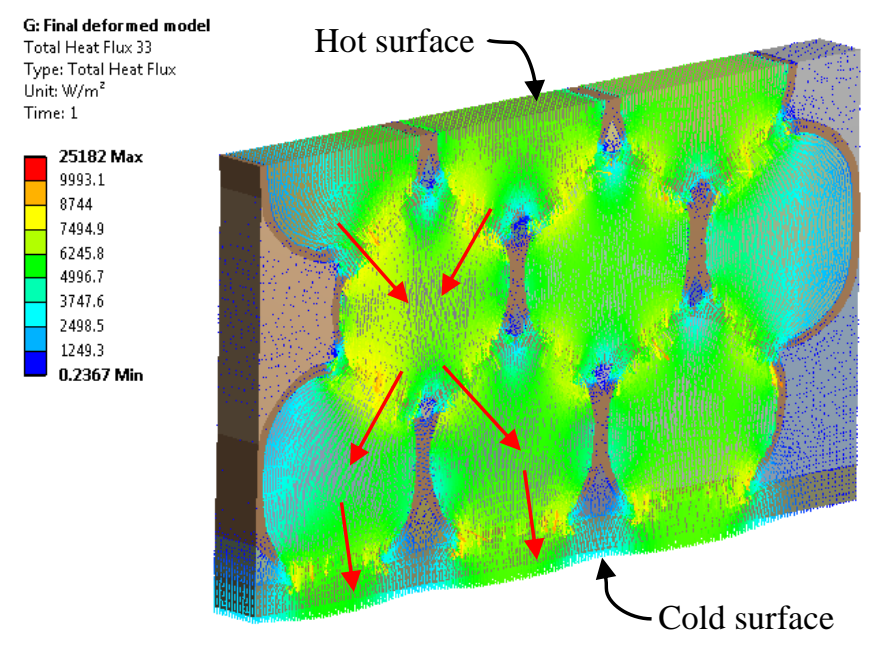

b)

Fig. 9. (a) Winding segment with sampled paths (b) Heat flux flow through deformed winding segment

In Fig. 9, the steady state FEA thermal modelling approach is shown. The coil hottest point was assumed to be in the middle layer of the winding. By setting up temperature boundary conditions for top and bottom surfaces of the deformed winding segment, heat flow is obtained across the slab. The deformed conductor shape, obtained from quasistatic explicit dynamic simulations in Section IV, was used to investigate heat flows through the winding after compression. Heat flux density samples are obtained along the paths shown in Fig. 10 for only first five paths. Temperature gradient was provided with $\Delta T=20^{\circ} \mathrm{C}$ for the top and bottom faces of the compressed winding segment. As thermal conductivity is a function of temperature gradient and heat flux density for the certain dimensions of the geometry, each path would have different effective thermal conductivity due to varying heat flux densities along the paths. The average thermal conductivity is calculated by applying (2) after heat flux density data along individual paths are obtained.

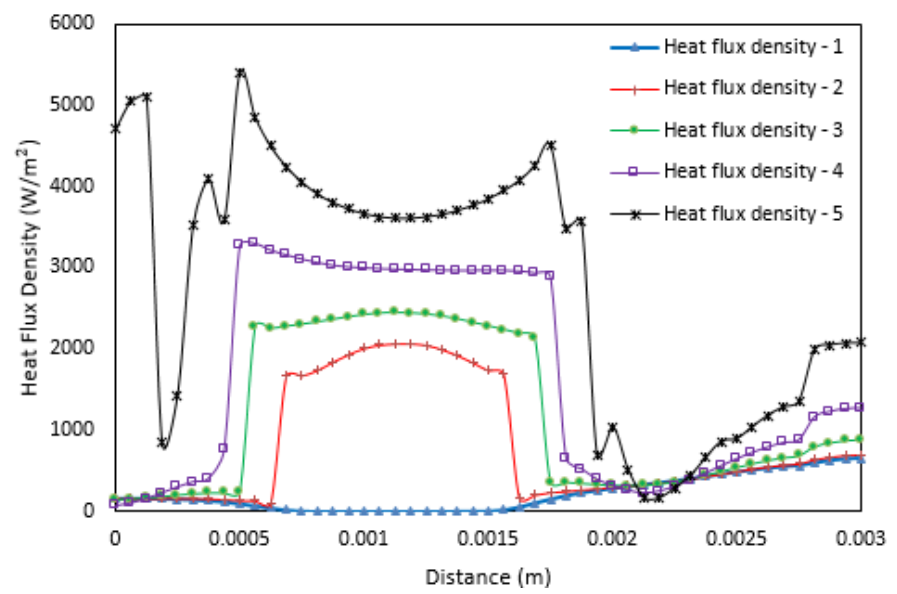

Fig. 10. Variation of heat flux density along the sampled heat flow paths 
The equivalent slot thermal conductivity using steady state FEA simulations is predicted to be $0.64 \mathrm{~W} / \mathrm{mK}$ in the radial direction. Heat flow in this case was considered in only one dimension, although the true nature of heat flow is threedimensional. Axial heat flow inside the winding was not taken into account as thermal conductivity is known to be higher in this direction.

\section{B. Short Time Transient Thermal Tests}

The thermal resistance of windings can be predicted by a first order thermal model [21-22], whereas the thermal resistance between the winding and stator lamination can be calculated by short time transient tests [19]. The test has to be finished when lamination temperature increases by about $1{ }^{\circ} \mathrm{C}$ [19] and stator winding temperature should be recorded during the test. The length of test is hence mainly dictated by physical size of a component. Over this short time, the thermal time constant of the first order system will be only dependent on heat flow by conduction and temperature response of the model can thus be used to predict thermal conductivity.

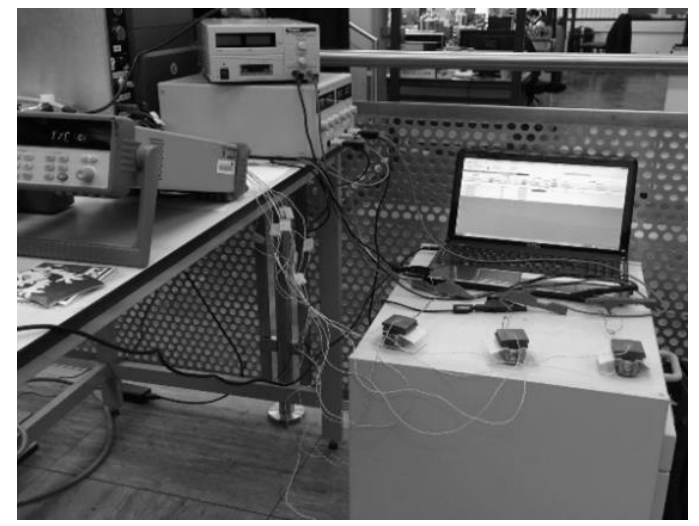

Fig. 11. Experimental setup for testing single tooth ISG windings

Equivalent thermal resistance, $R_{e q}$ and capacitance $C_{e q}$ of the winding are obtained from thermal tests and calculations. $C_{e q}$ can be either calculated by using motor design data or can be measured by performing steady state thermal tests. Since material physical and thermal properties are known for the proposed ISG single tooth windings, $C_{e q}$ was calculated using winding specific heat, mass density and volume, including both copper and insulation. $R_{e q}$ can be determined by minimizing the error between short time temperature increase and temperature response of the first order model. Thermal time constant monitoring is required to estimate $R_{e q}$ accurately.

Fig. 11 shows the short time transient tests being carried out in the laboratory by injecting $4 \mathrm{~A}$ dc into a single tooth ISG winding with an initial resistance of $0.26 \Omega$. Thermocouples of K-type were used to monitor temperature variation every $500 \mathrm{~ms}$ in winding and tooth. The test was finished in 300 seconds by monitoring tooth temperature increase $\left(\approx 1^{\circ} \mathrm{C}\right.$ increase $)$. The parameters of the first order system are given in Table VI.

TABLE VI. PARAMETERS OF FirST ORDER MODEL

\begin{tabular}{|c|c|c|}
\hline$R_{e q}$ & $C_{e q}$ & $\tau$ \\
\hline 3.5665 & 80.77 & 288.06 \\
\hline
\end{tabular}

Short time test results are compared to the temperature response of the first order model in Fig. 12, showing the accuracy of the model.

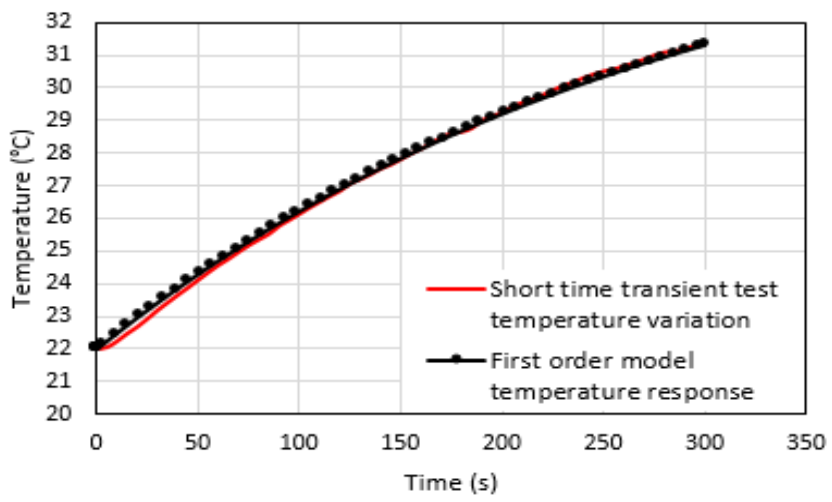

Fig. 12. Comparison of first order model and short time transient tests

Once $R_{e q}$ is determined, equivalent thermal conductivity of winding insulation system can be determined considering equivalent insulation system is a barrier between bulk copper in the slot and tooth. Since the proposed machine has a double-layer concentrated winding, $R_{e q}$ is divided into two parallel thermal resistors, each representing one side of the insulation around the single tooth winding. Total volume of the insulation was calculated and considered to be a single insulation system around bulk copper and the thermal conductivity of winding insulation system is written:

$$
k_{e q}=\frac{L}{R_{e q} \times A}
$$

where $L$ is insulation thickness and $A$ is surface area of the insulation.

The equivalent thermal conductivity of the insulation system was calculated to be $0.1308 \mathrm{~W} / \mathrm{mK}$. As equivalent width of copper around the insulation system can be also estimated, equivalent thermal resistance of the slot is calculated by adding copper and insulation system thermal resistances in series. The effective thermal conductivity of copper and insulation system together was estimated to be $0.526 \mathrm{~W} / \mathrm{mK}$ in the compressed coil.

Short time transient tests of the random wound ISG teeth with 0.57 slot fill factor were carried out and the effective thermal conductivity of the winding was measured as $0.283 \mathrm{~W} / \mathrm{mK}$. Thus, $85 \%$ effective thermal conductivity 
improvement was achieved with the compressed ISG teeth in comparison to the original winding.

The deformed geometry thermal conductivity prediction of $0.64 \mathrm{~W} / \mathrm{mK}$ is quite reasonable, as thermal conductivity is usually lower in experiments due to un-avoidable air gaps between winding materials.

Temperature differences at steady state between the tooth and winding in Fig. 13 demonstrate that average thermal conductivity is improved for the compressed winding as temperature difference is about $8.5^{\circ} \mathrm{C}$ for the conventional case and about $4.8^{\circ} \mathrm{C}$ for the compressed winding. The greater the temperature difference, the smaller winding thermal conductivity if other thermal parameters such as natural convection and heat capacity are similar. To ensure this condition, transient thermal tests were performed simultaneously in the same environmental condition for the compressed and un-compressed ISG teeth.

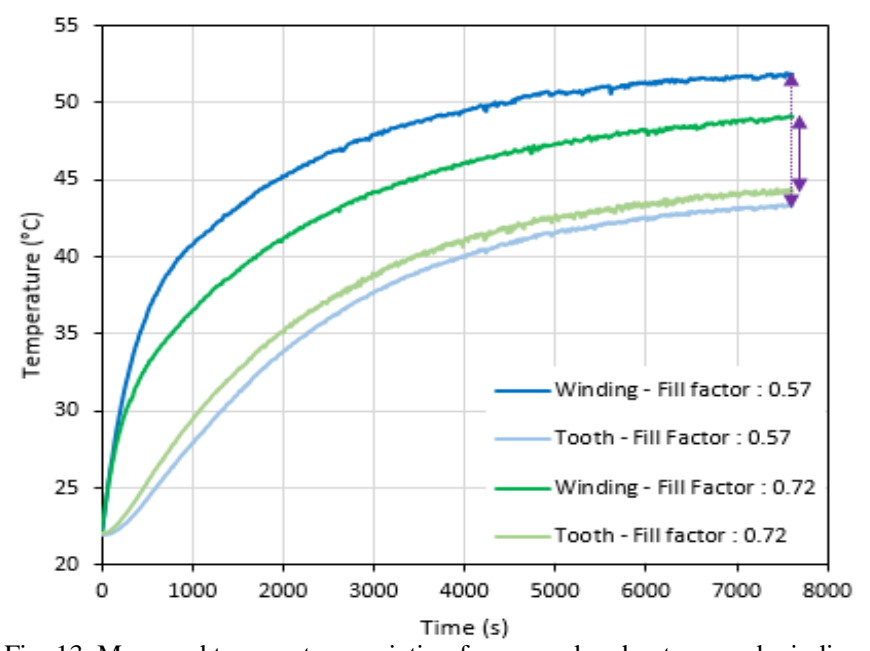

Fig. 13. Measured temperature variation for pressed and not-pressed winding

\section{CONCLUSION}

In this paper, a 21 slot -16 pole asymmetric integrated starter generator was proposed and used as a case study to investigate mechanical and electrical integrity and thermal performance of compressed stator windings. On-tooth pressing was successfully applied on the 91 turn single tooth windings with $1.25 \mathrm{~mm}$ Grade-2, copper wires. The proposed compression method avoids end winding deformation, although flattened magnet wire surfaces were observed in the main winding.

A 0.73 fill factor was obtained, where material fracture was not observed in quasi-static explicit dynamic simulations and experimental coils were checked for electrical integrity. Simulated deformed coil profiles were subsequently used as an input to steady state FEA thermal simulations where effective thermal conductivity of the winding was calculated to be $0.64 \mathrm{~W} / \mathrm{mK}$. Short time transient thermal tests have been performed to measure winding thermal conductivity as
$0.526 \mathrm{~W} / \mathrm{mK}$. Compared to the original winding at 0.57 fill factor, thermal conductivity was improved by $85 \%$ and copper losses reduced by $23 \%$.

\section{REFERENCES}

[1] Wen Ding and Deliang Liang "A Fast Analytical Model for an Integrated Switched Reluctance Starter/Generator" IEEE Transactions on Energy Conversion, Vol. 25, No. 4, December 2010

[2] J. F. Bangura, "Directly Coupled Electromagnetic Field-Electric Circuit Model for Analysis of a Vector-Controlled Wound Field Brushless Starter Generator", IEEE Transactions on Energy Conversion, Vol. 26, No.4, December 2011

[3] Chau, K.T.; Chan, C.C.; , "Emerging Energy-Efficient Technologies for Hybrid Electric Vehicles," Proceedings of the IEEE, vol.95, no.4, pp.821-835, April 2007

[4] Wang, C. F.; Jin, M. J.; Shen, J. X.; Yuan, C.; , "A Permanent Magnet Integrated Starter Generator for Electric Vehicle Onboard Range Extender Application," IEEE Transactions on Magnetics, vol.48, no.4, pp.1625-1628, April 2012

[5] Baker, N.J.; Atkinson, G.J.; Washington, J.G.; Mecrow, B.C.; Nord, G.; Sjoberg, L. , "Design of high torque traction motors for automotive applications using modulated pole SMC machines "IET International Conference on Power Electronics, Machines and Drives (PEMD 2012)

[6] M. C. Kulan, N. J. Baker and J. D. Widmer, "Design of a high fill factor permanent magnet integrated starter generator with compressed stator windings," 2016 XXII International Conference on Electrical Machines (ICEM), Lausanne, 2016, pp. 1513-1519.

[7] A. G. Jack, B. C.Mecrow, P. G. Dickinson, D. Stephenson, J. S. Burdess, N. Fawcett, and J. T. Evans, "Permanent magnet machines with powdered iron cores and pressed windings," IEEE Trans. Ind. Appl., vol. 36, no. 4, pp. 1077-1084, Jul./Aug. 2000.

[8] J. D. Widmer, C. M. Spargo, G. J. Atkinson and B. C. Mecrow, "Solar Plane Propulsion Motors With Precompressed Aluminum Stator Windings," in IEEE Transactions on Energy Conversion, vol. 29, no. 3, pp. 681-688, Sept. 2014.

[9] Widmer JD, Martin R, Mecrow BC "Pre-Compressed and Stranded Aluminium Motor Windings for Traction Motors", IEMDC 2015.

[10] Lee Huei-Huang, "Finite Element Simulations with Ansys Workbench 14," SDC Publications, 2012.

[11] Alberti, L.; Barcaro, M.; Pré, M.D.; Faggion, Adriano; Sgarbossa, L.; Bianchi, N.; Bolognani, S., "IPM Machine Drive Design and Tests for an Integrated Starter-Alternator Application," in Industry Applications, IEEE Transactions on , vol.46, no.3, pp.993-1001, May-June 2010

[12] Cai, W., "Comparison and review of electric machines for integrated starter alternator applications," in Industry Applications Conference, 2004. 39th IAS Annual Meeting. Conference Record of the 2004 IEEE , vol.1, no., pp.393, 3-7 Oct. 2004

[13] Mirahki, H.; Moallem, M., "Design improvement of Interior Permanent Magnet synchronous machine for Integrated Starter Alternator application," in Electric Machines \& Drives Conference (IEMDC), 2013 IEEE International, vol., no., pp.382-385, 12-15 May 2013

[14] Yang, S; Baker, N.J.; Mecrow, B.C.; Hilton C; Sorriyakumar, G; Kostic-Perovic D; Fraser, A, "Cost reduction of a permanent magnet in-wheel electric vehicle traction motor", IEEE International Conference on Electrical Machines (ICEM 2014)

[15] "Abaqus/Explicit: Advanced Topics: Quasi-Static Analysis Lecture 5," Online: imechanica.org/files/15-quasi-static.pdf [Accessed: August 06, 2015]

[16] "CFD Meshing with Ansys Workbench Tutorial" Online: caeai.com/sites/default/files/CFD_Meshing_CAEA.pdf [Accessed: June 16, 2016]

[17] IEEE Recommended Practice for Testing Insulation Resistance of Electric Machinery," in IEEE Std 43-2013 (Revision of IEEE Std 432000), vol., no., pp.1-37, March 62014

[18] A. Boglietti, E. Carpaneto, M. Cossale, A. Lucco Borlera, D. Staton and M. Popescu, "Electrical machine first order short-time thermal transients model: Measurements and parameters evaluation," IECON 
2014 - 40th Annual Conference of the IEEE Industrial Electronics Society, Dallas, TX, 2014, pp. 555-561.

[19] A. Boglietti, E. Carpaneto, M. Cossale, M. Popescu, D. Staton and S. Vaschetto, "Equivalent thermal conductivity determination of winding insulation system by fast experimental approach," 2015 IEEE International Electric Machines \& Drives Conference (IEMDC), Coeur d'Alene, ID, 2015, pp. 1215-1220.

[20] N. Simpson, R. Wrobel and P. H. Mellor, "Estimation of Equivalent Thermal Parameters of Impregnated Electrical Windings," in IEEE Transactions on Industry Applications, vol. 49, no. 6, pp. 2505-2515, Nov.-Dec. 2013.

[21] A. Boglietti, E. Carpaneto, M. Cossale and S. Vaschetto, "StatorWinding Thermal Models for Short-Time Thermal Transients: Definition and Validation," in IEEE Transactions on Industrial Electronics, vol. 63, no. 5, pp. 2713-2721, May 2016.

[22] A. Boglietti, E. Carpaneto, M. Cossale and A. Lucco Borlera, "Stator thermal model for short-time thermal transients," 2014 International Conference on Electrical Machines (ICEM), Berlin, 2014, pp. 14151421.

\section{BIOGRAPHIES}

Mehmet C. Kulan received the BSc degree in electrical and electronics engineering from Bilkent University, Ankara, Turkey in 2011 and MSc degree from the University of Newcastle Upon Tyne U.K., in 2013, where he is currently working toward the Ph.D. degree as part of Electrical Power Group, School of Electrical and Electronic Engineering.

Nick J. Baker received a MEng Degree in Mechanical Engineering from Birmingham University, UK, in 1999 and a Ph.D. from Durham University U.K in 2003 for work in electrical machine design for marine renewable energy devices. $\mathrm{He}$ is presently a Lecturer at Newcastle University's Electrical Power Group. Nick is a machine designer with research projects across the automotive, aerospace and renewable energy sector. 